\title{
Resúmenes de Literatura Mundial
}

\author{
Dres.: López Alfonso, Riaño Mario, Uribe L., Sierra A.
}

\section{ACELERACION DE LA MADURACION PULMONAR FETAL} \section{1.}

Edward Bishop. Obstetrics and Gyn.

Riesgos fetales y neonatales. Todos los estudios se han hecho sobre animales; en éstos, una dosis prolongada de corticoides produce inhibición de la síntesis de DNA, alteraciones del SNC, bajo peso al nacer, disminución de la talla corporal, incremento de muerte fetal, alteración del sistema inmunológico y alteraciones del sistema enzimático del recién nacido. Como efecto inmediato se ha hallado hipoglicemia en los niños.

Las siguientes son indicaciones razonables para el uso de corticoides para la maduración pulmonar: 1 . Edad gestacional entre 28 y 32 semanas, 2. Relación
L/E desconocido o bajo, 3. Embarazo que puede ser continuado. 4. Ausencia de otras contraindicaciones.

Los siguientes pueden ser contraindicaciones para el uso de esos agentes: 1. Irilposibilidad para demorar el trabajo de parto. 2. Relación L/E adecuada. 3. Necesidad de un parto inmediato. 4. Presencia de infección materna, 5. Diabetes materna. 6. Hipertensión. 7. Concomitante uso de agentes tocolíticos.

En conclusión, el uso de los corticosteroides para la prevención de los problemas pulmonares es un notorio avance en la medicina reproductiva. Sin embargo, no son una panacea y su uso puede no influir sobre un buen criterio obstétrico o pediátrico.

\section{VIGILANCIA DEL MOVIMIENTO FETAL}

\author{
Dr. Mortiner G. Rosen y Col.
}

Ginecología y Obstetricia "Temas Actuales". Vol. 2 de 1979. Pág. 327336.

El movimiento fetal es el parámetro más antiguo utilizado para estudiar el feto. Técnicas usadas. Observación madre-doctor, electromecánicas (Métodos pasivos-tocodinamométro) registros activos (ultrasonido) Tipo de movimientos: a) de duración mayor de 1 segundo, dados por movimientos de tórax, tronco, 
extremidades (perceptibles por la madre). b) de duración menor de un segundo, dado por movimientos de respiración (no perceptibles por la madre); es útil el ultrasonido.
La no percepción de movimientos fetales por la madre, que antes los sentía, es índice de sufrimiento fetal y puede preceder a la muerte fetal en un período aproximado de 12 horas.

\title{
ANORMALIDADES DE LA FASE ACTIVA DE TRABAJO DE PARTO
}

\author{
Reconocimiento y Tratamiento
}

Clinical Obstetrics and Gynecology Vol. 25, No. 1 marzo 82. Autores: William O. Brien Robert Cefalo.

Para las anormalidades de la fase activa de parto existen sólo cinco métodos de tratamiento: Observación y soporte emocional y fisiológico, sedación materna, analgesia, estimulación de las contracciones uterinas y cesárea. El reconocimiento de las anormalidades se basó en valoración cervical, presión intrauterina y duración, intensidad y calidad de contracciones uterinas.

La disfunción primaria la definieron como dilatación menor de $1,5 \mathrm{~mm} / \mathrm{h}$ en multíparas y $1,2 \mathrm{~mm} / \mathrm{h}$ en nulíparas.
Detención secundaria se definió como suspensión del trabajo durante 2 horas. Los desórdenes combinados se definieron como detención más disfunción primaria. De acuerdo al análisis manométrico se definieron 2 anormalidades: hipotonía e hipertonía. En resumen, se concluyó que es efectiva la inducción con oxitocina en disfunciones por detención secundaria, descartando la desproporción CP absoluta, las distocias de cuello verdaderas y las malposiciones fetales. En cuanto al tratamiento de hiperton ías existe una gran controversia. Es necesaria la valoración previa con pelvimetría y estudio radiológico ante la presencia de anormalidades de la fase activa de trabajo de parto.

\section{LEIOMIOMATOSIS UTERINA, ETIOLOGIA, SINTOMATOLOGIA Y MANEJO}

Bultran, VC. and Reiter, RC. Fertil Steril. 1981 Sept.-Oct; 36 (4): 433-444.

El leiomioma uterino ocurre en una de cada 4-5 mujeres en edad reproductiva y es el tumor pélvico sólido más común en la mujer; la etiología y sintomatología son pobremente conocidas y falta uniformidad para su manejo.
Etiología: Towsend y Col. encontraron que todas las células de un leiomioma poseen un mismo tipo de glucosa o fosfato deshidrogenasa, pero el tipo puede variar de un tumor a otro, en el mismo útero. Se sugiere que los leiomiomas son de origen unicelular. Tres factores pueden influenciar la rata de crecimiento del leiomioma: estrógenos, hormona del crecimiento, progesterona. 
La tendencia de los tumores a surgir durante la vida reproductiva, a crecer durante el embarazo y a regresar durante la menopausia, implican a los estrógenos como factor en la patogénesis del tumor. Se ha encontrado mayor cantidad de receptores estrogénicos en el tejido tumoral, alteraciones en el metabolismo del estradiol dentro del tumor e hiperplasia glandular endometrial en las márgenes submucosas del tumor, sugiriendo hiperestrogenismo.

Hormona del crecimiento: Se ha demostrado efecto sinérgico entre la $\mathrm{HC}$ y el estradiol en ratas para inducir aumento del peso del útero. Varios autores han encontrado una mayor respuesta a la $\mathrm{HC}$ en mujeres negras que en blancas, cuando se administra una carga de glucosa; esto podría explicar por qué existe una incidencia 3 a 9 veces mayor de leiomiomas en negras que en blancas. No hay evidencia que la leiomiomatosis esté aumentada en acromegálicas; durante el embarazo el lactógeno placentario con estructura $y$ actividad similar a la $\mathrm{HC}$, en efecto sinérgico con estradiol, puede ser el responsable de la alta incidencia de crecimiento de los leiomiomas.

Algunos estudios han sugerido que la progesterona puede inhibir el crecimiento de los leiomiomas, previniendo la formación o haciendo regresar el tamaño de los tumores, especialmente cuando se administra a grandes dosis. Se ha sugerido que la concentración de receptores de progesterona es más baja en los leiomiomas. Otras teorías sugieren tendencia genética a desarrollar tumor, o alteraciones en el riego sanguíneo del tumor.

Sintomatología: El $25 \%$ de los miomas uterinos producen síntomas, que dependen del número, tamaño y localización del tumor. La menorragia presente en el $3 \%$ de los casos parece causada por ulceraciones del tumor submucoso, en los que es más severa; por asociación con ciclos anovulatorios, gran tamaño de mioma, interferencia con la contractilidad normal uterina, aumento de la presión venosa del miometrio adyacente al tumor causando estasia venosa.

El leiomioma es causa poco frecuente de infertilidad $(24 \%)$, que parece ser más alta entre negras. Puede causar adherencias, interferir con la contractilidad uterina inducida por las protaglandinas para el transporte de los espermatozoides; causar hipermotilidad miometrial por irritación, degeneración o torsión de un mioma; obstrucción tubárica por localización cornual; obstrucción cervical, defectos de nidación o altera la irrigación del huevo, dándose aborto. El hacer miomectomía corrige la infertilidad solo en $50 \%$ de las pacientes. En el $41 \%$ de los embarazos con miomatosis se produce aborto por irritación miometrial, deformidad de la cavidad o alteraciones en el flujo sanguíneo. También causa parto prematuro, obstrucción del canal del parto, presentaciones anormales, hemorragias e infección del tumor. La miomectomía reduce las pérdidas de $41 \%$ al $19 \%$.

El dolor pélvico se presenta en el $34 \%$ de los casos pero es atribuido a adherencias, EPI, endometriosis, diverticulosis o Ca de ovario, Policitemia. Parece que el tumor produce eritroproyectina que estimula la producción de glóbulos rojos.

Ascitis: Más frecuente en los miomas parásitos del epiplón.

Ocasionalmente pueden causar polaquiuria, retención o incontinencia urinaria, constipación o franca obstrucción intestinal. Ulceraciones del tumor con sobreinfección, inversión uterina en los miomas submucosos, degeneración sarcomatosa más frecuente después de los 50 años y ocurre en 1: 200 casos principalmente en los tumores de crecimiento rápido. 
Técnicas de miomectomia: En la realización de miomectomía hay dos cosas importantes: minimización del sangrado y la prevención de adherencias postoperatorias. Para disminuir el sangrado se sugieren los torniquetes a nivel del segmento uterino bajo que ocluyan los vasos uterinos, aflojarlos cada 10 minutos para evitar daños en los tejidos o las estructuras vasculares, o shock postoperatorio por liberación de histamina. La aplicación de vasopresores no es usada por los autores que parece no encuentran ventajas. Los autores sugieren hacer una incisión en la línea media, verticalmente, por ser el área menos vascular del útero, con lo que se puede disminuir el sangrado. Cuando es posible la compresión manual del segmento uterino bajo es también de ayuda.

La incisión vertical mediana anterior del útero tiene menos riesgo de causar adherencias $\mathrm{y}$ comprometer trompas $\mathrm{V}$ ovarios. Para los miomas en cara posterior sugieren prolongar la incisión hasta el fondo uterino, o hacer una incisión en el segmento uterino bajo posterior; también abogan por la enucleación transcavitaria, a través de una incisión anterior. El cierre del miometrio lo hacen con vicryl puntos separados. La serosa con vicryl 4-0 sutura continua. También utilizan colgajos de peritoneo, epiplón, dextran al $10 \%$ en el momento de cerrar peritoneo, para ejercer efecto de flotación, decadrón y fenergan en el postoperatorio. Los resultados no han sido muy satisfactorios.

\section{Plan de manejo de los leiomiomas uterinos}

Cuando el tamaño del útero semeja menos de 10-12 semanas de embarazo sólo se requiere observación cada 6 meses en pacientes asintomáticas; cuando semeja más de 10-12 semanas o el crecimiento es rápido, el manejo depende de los deseos de fertilidad. El crecimiento se considera rápido cuando gana un ta- maño como para 6 semanas en un año o menos. Si se desea fertilidad se deja una prueba de embarazo pues hay quienes cursan embarazo sin complicaciones. Si el crecimiento es rápido se debe hacer miomectomía temprana. Si no hay intereses en concepción pronto se debe hacer miomectomía pues las complicaciones son mayores con el mayor tamaño del útero y el éxito para la fertilidad disminuye. La miomectomía temprana disminuye la necesidad de histerectomía y preserva la fertilidad. Cuando no se desea la fertilidad y el útero es como para 10-12 semanas o más de gestación o el crecimiento es rápido, se aconseja la histerectomía, pues los úteros muy grandes incrementan el riesgo de lesionar estructuras adyacentes; además, se debe pensar en el riesgo de sarcoma. Pacientes de 30 años con úteros menores y sin crecimiento rápido se pueden manejar conservadoramente. En pacientes postmenopáusicas se recomienda la histerectomía con SOB.

Pacientes sintomáticas: $\mathrm{Si}$ no se encuentra otra causa de infertilidad o aborto se deberá practicar miomectomía, asumiendo que todo mioma con más de dos centímetros es causa potencial de aborto o infertilidad. Los tumores intramurales o submucosos son los que más causan la infertilidad. Los subserosos sólo cuando causan obstrucción tubárica. Cuando la mujer es menopáusica, no desea fertilidad o los síntomas son incontrolables 0 debilitantes se deberá practicar curetaje e histerectomía; una excepción es el dolor que cede con analgésicos comunes o el sangrado que cede al remover el mioma submucoso pedunculado. La conducta conservadora se justifica porque muchos miomas tienden a regresar en la menopausia.

Los anticonceptivos orales se contraindican en mujeres con leiomiomas por su efecto potencial de favorecer el crecimiento del tumor. Los dispositivos in- 
trauterinos pueden causar aumento del sangrado o no ser efectivos en tales circunstancias. Se pueden colocar en estos casos en prueba pero con la advertencia de tener que retirarlo en caso de aumentar el sangrado.

\section{EFECTOS DE LOS ESTROGENOS Y PROGESTAGENOS SOBRE LA BIOQUIMICA Y MORFOLOGIA DEL ENDOMETRIO POST-MENOPAUSICO}

M.I. Whitehead, P.T. Towsend, J. Pryse-Davies, T.A. Ryder y R.J.B. King. The new england journal of medicine. Vol. 305, No. 27, Dic. 31, 1981; pp. 1599-1605.

Para estudiar los efectos de los estrógenos exógenos sobre el endometrio post-menopáusico, y para determinar el curso de tiempo y la dosis mínima de progestágenos agregada necesaria para oponerse a la estimulación estrogénica, se obtuvieron muestras de endometrio de mujeres post-menopáusicas sintomáticas, que estaban siendo tratadas con varias preparaciones de estrógenos y progestágenos. Para comparación, estudios idénticos fueron llevados a cabo en muestras de mujeres premenopáusicas en las fases proliferativa y secretoria de su ciclo. Los autores concluyen que muchas preparaciones estrogénicas someten al endometrio a un estímulo potente. La noretindrona $y$ el norgestrel son protectores, a causa de que contrarrestan los efectos proliferativos de los estrógenos, pero las dosis recomendadas actualmente diarias para estos progestágenos, pueden ser reducidas bastante, sin pérdida de la respuesta.

\section{METRORRAGIA EN LA MENOPAUSIA}

Dr. R. Don Cambrell, Jr. Ginecología y Obstetricia. Temas Actuales. Abril de 1977. Pág.: 131-45.

La presencia de sangrado post-menopáusico hace pensar en cáncer en la mayoría de las pacientes. Los estudios demuestran incidencia de $13 \%$ de cancér. El diagnóstico por citología, biopsia en consultorio, con cureta de Novack o aspiración se hace en el 90-100\%. La obesidad, infecundidad, hepatopatías, ovarios poliquisticos virilizantes, son factores predisponentes, al igual que los anticonceptivos secuenciales. El tratamiento, una vez descartado proceso neoplásico, se dará a base de progestáge- nos, o terapia en base de estrógenoprogesterona, en aquellas pacientes que toman estrógenos para sintomátología menopáusica y que presentan sangrado por supresión estrogénica.

Se ha reportado aumento de la morbilidad post-histerectomía vaginal en premenopáusicas, en relación con las postmenopáusicas. Se realizó estudio bacteriológico vaginal tomando pacientes premenopáusicas de 19 - 36 años y post-menopáusicas, mayores de 55 años. divididas en dos grupos: sin medicamento $y$ con ingestión de estrógenos conjugados.

\section{GENITAL BACTERIOLOGY}

A comparative study of premenopausal with postmenopausal women. New- ton G. Osborn et al. Am. J. Obstet. Gynecol. Sept. 15 de 1979. Pág. 195-7. 
Se tomaron cultivos de vagina $y$ endocervix. No se encontraron diferencias significativas en los organismos aislados, en los distintos grupos estudiados, como en las muestras tomadas de vagina o endocervix, para cada paciente. Descartan la flora vaginal como determinante de aumento de riesgos post-histerec- tomía vaginal, para originar cuadros infecciosos. Suponen debe existir factores más bien relacionados con la edad, incrementos de sangrados menstruales en las premenopáusicas, reducida vascularización en la post-menopáusica o posibles cuadros de infección sub-clínica en la premenopáusica.

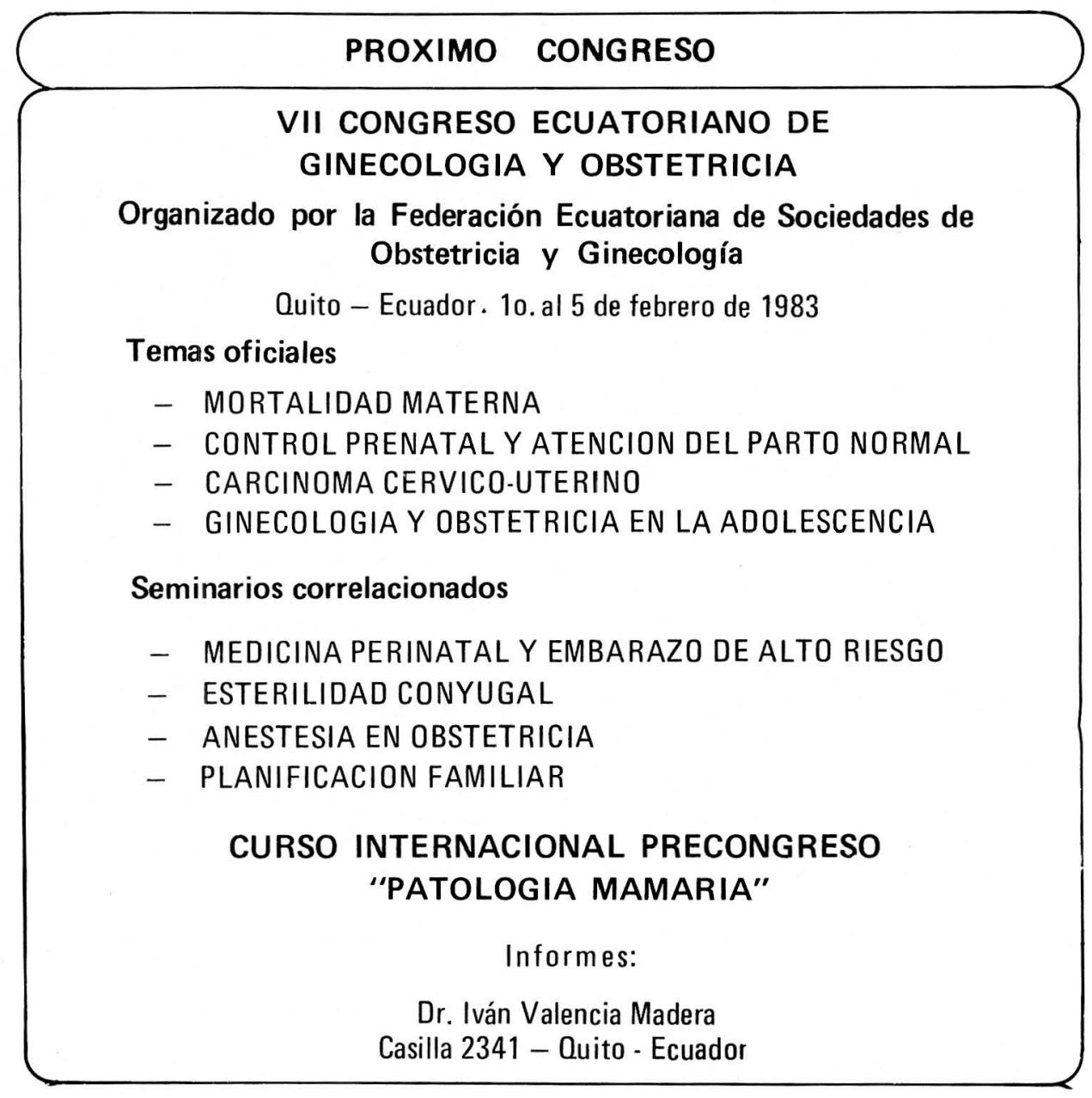

